\title{
HUMAN RELIABILITY USING THE FAULT TREE ANALYSIS. A CASE STUDY OF A MILITARY ACCIDENT INVESTIGATION
}

\author{
Florin NICOLAE, A. COTORCEA, Marian RISTEA, Dinu ATODIRESEI \\ "Mircea cel Bătrân" Naval Academy, Constanța, Romania \\ nicolae_florin_m@yahoo.com
}

\begin{abstract}
The work integrates the human error term in the broader concept of human performance analysis. The main issues associated with human error and human reliability are highlighted step by step, resulting from the review of literature, from the perspective of the relationship between risk and safety. To assess the risks arising from human error and to reduce vulnerability of work, methods derived from the probabilistic assessment of the work safety systems are used. To identify the risks caused by the human error, the authors propose the Fault Tree Analysis (FTA) method. The paper reveals the way the method is used for identifying the critical subsystems for the functioning of a given system and analyzes how unwanted events and their causes arise and occur. Also, a case study that is investigated throuhg the FTA method and that consists in the analysis of an accident that occurred in Evangelos Florakis naval logistics base from Cyprus, is presented.
\end{abstract}

\section{Keywords: human error, Fault Tree Analysis, logistics}

\section{Introduction}

The presence of the human factor in the vast majority of actions and activities is a certainty, and human error will always be associated with events that have resulted in accidents. This relationship is reflected widely in many specialty publications, the level of complexity being detailed from both theoretical and practical perspective $[1,2]$. Pheasant proposes a simpler definition of human error in the sense of malpractice [3]. James Reason, one of the great theorists in this field, defines human error as a concept that characterizes the events or a sequence of activities in which the human factor that is involved does not meet the target at planned performance parameters in the absence of unexpected external disturbance factors [4]. Sanders and McCormick propose a definition centered on the effect of human error [5]. Wickens in turn, emphasizes the relationship between the human error and the associated consequences on safety [6].

The analysis of major accidents in the light of the views expressed above reveals the human error as a wrong decision or an inappropriate behavior. Taylor shows that in some cases the same action can be regarded as correct by the person who performs it and incorrect by another [7]. Problems associated with the various approaches of the concept of human error exist in the academic world, demonstrating its utility for the explanation and understanding of failures, accidents or damages. In conclusion, the human error represents the performing or omitting a human action, or a psychological state or activity that may be mis-spectrum with individual expectations, and/or behaviours/intentional conditions, and/or rules or standards, and/or potential or actual results and/or other ratings. 


\section{Human error and human reliability}

In its development, the human society has manifested a high interest for performance or failure in almost all areas, and each time the analysis could be done in compliance with human error. The concept of human error is a very broad topic of analysis being used in a close relationship with the safety and risk terms. The theoretical approach of the term involves the use of documented information about the types of human error. On the other hand, the practical approach to the problems associated with human error aims to identify the mechanisms that underlie the occurrence of errors.

Human error is often associated with effects, evidenced by major accidents, disasters recorded in various fields: nuclear energy, space engineering, offshore engineering and, not least, the military, including that of ensuring logistics. The magnitude of effects and implications on human communities or the environment put us in a position to consider that human error can lead to extended effects in space and time. In the organizational psychology and occupational psychology, in recent years there have been various studies and analyzes of human error, which opened new research directions. These focus on the relationship human error - performance or human action failure, geared to predict, prevent and reduce errors. From the first steps of man on the moon, the relationship between performance and correct bias, reflected by Reason, is a characteristic of the human activity [4]. It is obvious that the technological progress made in the last 50 years requires a high volume of mathematical calculations, estimations and forecasts, which in turn, under overload, facilitate loss of data and information, which are the precursor of appearance and manifestation chain of errors.

An investigation of a large number of accidents made by specialists has concluded that the human error contributed to the initiation and escalation of catastrophic sequence of events, especially when the operator had to make decisions in a very short time. In other situations, the same analysis revealed that human action was the only way of defense that prevented the unforeseen event to turn into an accident.

Therefore, the impact of staff on a system performance receives new dimensions, requiring a new concept called human reliability, a concept used to evaluate the influence of human error on systems. The concept of human reliability is taken from the technical term reliability, term that is used today in many ways. From this perspective, the technical reliability represents all the qualitative characteristics of an entity/technical system expressed by the probability to perform a function imposed under the prescribed conditions for a long time, according to the purpose for which it was built.

In the same way, the human reliability is the ability of a human entity (person/ team/crew/organization) to achieve a set of functions/missions required in given conditions for a given time. Aware of the importance of the human factor, the European Economic Commission gave the following definition for human reliability: "body of knowledge on predicting, analyzing and reducing human errors, focusing on the man's role in an operation planning, maintenance and operation of the system" [8].

Scientific methods used to assess the human reliability are based on the assumption that human error, related to the actions of the individual human operator, can not provide a precise calculation for the effects of its impact. Also, the same conclusions can be drawn after major accident investigation reports. Their analysis will reflect that action errors are dependent on the broader context in which they occur and are more suggestive to the approach performed, being the conditions variability, as initiation signal/occurrence of an accident to human error probability. 
To assess risks arising from the human error and to reduce vulnerability of work, methods derived from the probabilistic assessment of the safety in work systems are used $[9,10]$. In summary, the evaluation phases of human reliability in conditions of a certain system of labour include: identifying the human error; assessing the human error in order to establish the likelihood of errors; limiting and mitigating human error and initiating necessary measures for optimizing the human reliability by reducing the probability of error. To assess the human reliability, the following definition, that the human error relates to an identifiable action, which may account for an undesired effect, must be considered [11]. There are numerous examples, an action outside the tolerance, a lack of action, while the human operator's performance limits are defined in the work system. Studies and research have been completed by the development of databases that can be used to determine the likelihood of human error. This approach has its limits, based on questionable assumptions about the human behaviour. Even if action errors are attributed to human entities (represented by individuals or teams), the evaluation is not objective because quantifiable sizes are missing. In this case, the human entity regarded as part of the work is mostly dynamic, and therefore, human errors are not similar to those of a technological process.

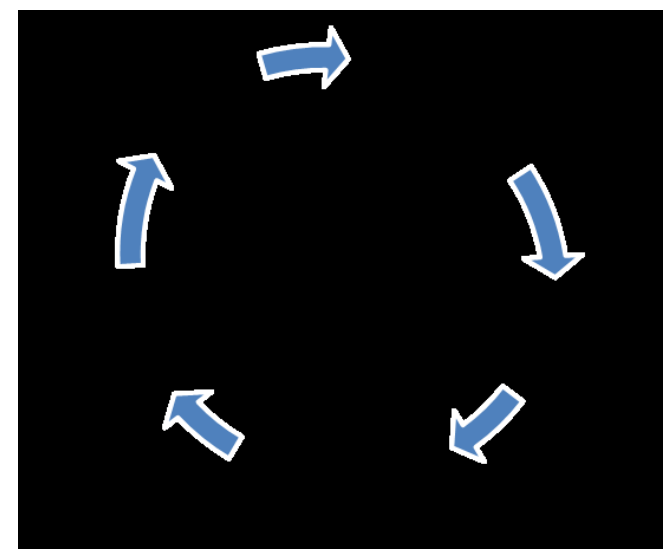

Figure 1: Decomposition of action method for human reliability analysis
The connection between the two types of errors exists only in algorithmic behaviours, whose performance is consistently high (air traffic controllers). In these conditions human action models are necessary in order to be used for work systems design or job task analysis [12].

Analysts who study this issue propose human actions decomposing in their constituent functions (figure 1). Step by step these functions are decomposed in components, for which functional relationships, that will facilitate the identification of incorrect/errouneous action that affect human reliability and, ultimately, will lead to accident, are described. Most times, for highly complex work systems, the investigation of human reliability is done for all stages that involve the human operator (design phase, operating level and management). The human error has a significant role in all stages of the life cycle of a work system.

\section{Fault Tree Analysis (FTA)}

One of the techniques often used in risk analyses, which implies the presence of the human factor, is the Fault Tree Analysis method (FTA). The Fault Tree is a calculation scheme constructed in relation with a state of failure (undesirable event such as an accident, damage, etc.), also known as a peak event.

The analysis is used to identify the most critical subsystems in the functioning of a given system or to analyze how unwanted events and their causes arise and occur. In most cases the Fault Tree Analysis is based on the results that allow the identification of potential possibilities of failure and assessment of their impact on the functioning of an entity (system, plant and equipment). FTA is used to improve operational safety by early phases of design of complex systems, and can be expanded to safety analyses of labour.

Starting from the top event established a priori, its causes or possible failures are being sought. Possible 
malfunctions of the system are identified step by step, moving from the upper level to the lower levels. At the basic level, identified causes represent the failure modes of components. Relations between the causes of events are summarized and visualized in a flowchart. Symbols, terminology and technique used in the construction of a Fault Tree are presented in detail in the literature [10].

\section{A Case Study: the explosion at} Evangelos Florakis naval base in Cyprus What happened?

The explosion at the Evangelos Florakis naval base in Cyprus was the biggest peacetime military accident recorded by NATO. The incident occurred on 11 July 2011 when 98 containers filled with explosives, stored outdoor for more than $2 \frac{1}{2}$ years under the scorching Mediterranean sun, exploded. The explosion killed 13 people and another 62 were seriously injured. Following the explosion, hundreds of buildings, located near the naval base, including the largest power plant in Cyprus were damaged. Following the accident, the entire country remained without electricity and the total damage was estimated to more than 2 billion $€$.

\section{The accident mechanism}

A set of factors had contributed to the mechanism that caused the accident. These factors were assigned to wrong decisions and actions taken by the human factor. The main factors that caused this accident were: acceptance from Cypriot state to take the ammunition despite the lack of a management plan (the first and most important factor); storing ammunition in the sun, outdoor (second factor); the refusal of Germany, the United Kingdom and the United States' intentions to manage or destroy ammunition (third factor). Another factor was the climate in Cyprus: the regime of humidity and high temperatures have led to degradation of munitions and primed detonation mechanism.

Construction of the Fault Tree Analysis (FTA). (RBD)

The Reliability Block Diagram

The Fault Tree Analysis, built in figure 2, shows that there were three main factors that triggered the disaster: (1) the acceptance of the Cypriot state to take ammunition and the refusal of removal and destruction offers, reflected by the lax policy in relation with NATO; (2) keeping ammunition outdoor, facilitated by inefficient management of the problem from the military perspective; (3) containers explotion, due to lack of supervision of ammunition and lack of a viable firefighting plan.

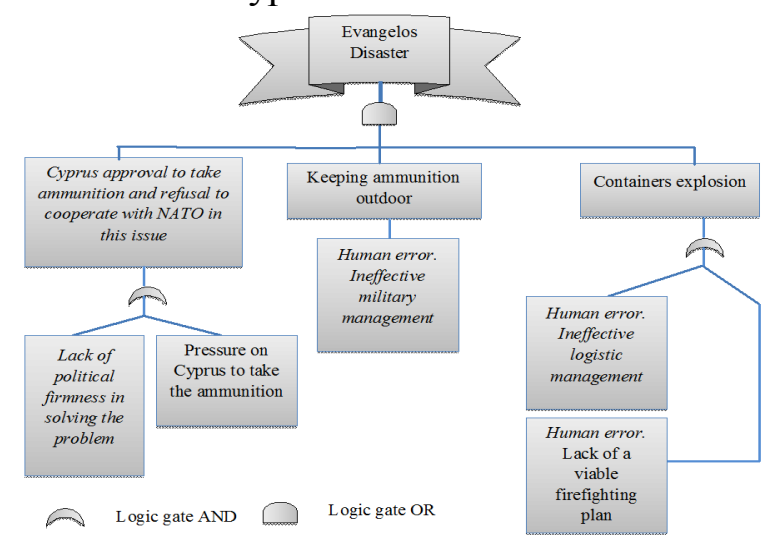

Figure 2: Fault Tree method applied to the Evangelos logistics base disaster 
The RB Diagram (figure 3) results from the Fault Tree Analysis, in which each logical AND gate is distributed in a parallel structure and each OR gate in a series of structure.

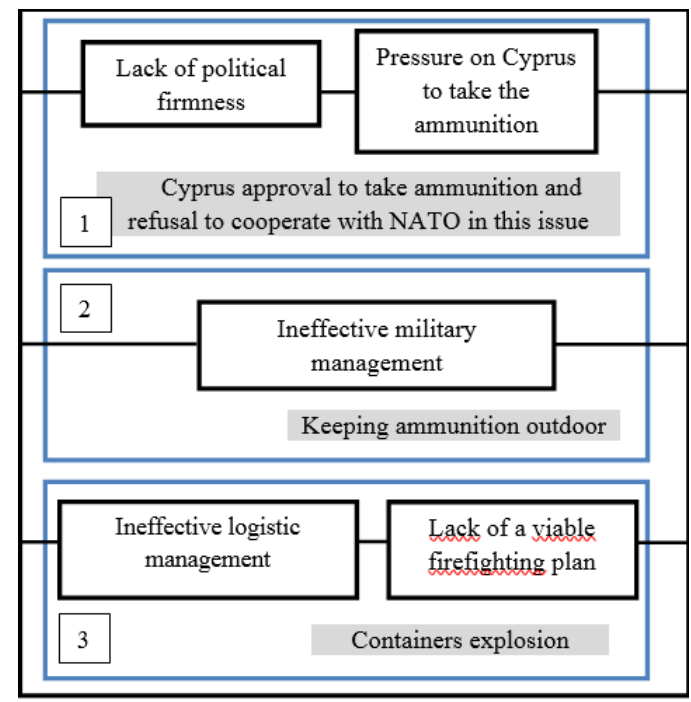

Figure 3: Reliability Block Diagram for Evangelos disaster

In the Block Diagram sequences 1 and 3 have the highest vulnerability and, consequently, the greatest contribution to Evangelos disaster. The analysis of the accident shows that the human factor was the main cause that led to the disaster, although causes that initiated the fire were not identified.

Negligence and mismanagement (political and military) have led to Evangelos disaster.

\section{Conclusions and Recommendations}

The paper highlights the key role of the human factor in managing all processes, production, service sector or activities with special character (military, in this case). The human reliability analysis must be phased for the entire lifecycle of a product or process, from the design stage and then production to operation and maintenance phase. The FTA method can be used both to improve the operating safety, yet at the design of complex technical systems and security analyses of labour. Research on the human reliability will be continued by the authors towards increasing the operational safety and the risk management.

\section{References}

[1] Singleton, W. T. Theoretical Approaches to Human Error. The Society's Lecture 1973 Given at Loughborough, on $29^{\text {th }}$ March 1973, Ergonomics, 16(6), 727-737, 1973.

[2] Ridley, J., \& Channing, J. (Eds.). Safety at work. Routledge, 2008.

[3] Pheasant, S. Ergonomics, Work and Health. Macmillan Press, Basingstoke, 1991.

[4] Reason, J. Human error. Cambridge: Cambridge University Press, 1990.

[5] Sanders, M.S., McCormick, E.J. Human factors in engineering and design. McGraw-Hill Book Company, 1987.

[6] Wickens, C.D., Lee, J.D., Liu, Y., \& Gordon-Becker, S. Introduction to human factors engineering. Pearson Prentice Hall, 1998.

[7] Taylor, D.H. The hermeneutics of accidents and safety. In: Rasmussen, J., Duncan, K., LePlat, J. (Eds.), New Technology and Human Error. Wiley, New York, NY, 1987.

[8] Poucet, A. Survey of methods used to assess human reliability in the human factors reliability benchmark exercise. Reliability Engineering \& System Safety, 22(1), 257-268.

[9] Kirwan, B. A guide to practical human reliability assessment. Taylor \& Francis, 1994.

[10] Nicolae, F. Risk management. Concepts. Methods. Applications (in Romanian: Managementul riscului. Concepte. Metode. Aplicații), Mircea cel Bătrân Naval Academy Press, Constanța, 2015.

[11] Swain, A. D. Comparative evaluation methods for human reliability analysis (GRS-71). Köln, Germany: Gessellschaft für Reaktorsicherheit, 1989.

[12] Dougherty, E. M. Jr. Human reliability analysis - Where shouldst thou turn? Reliability Engineering and System Safety, 29, 3, pp. 283-299, 1990. 